\title{
Short Communication: Effect of cryopreservation on ultrastructure and mitochondrial function of albino Pangasius catfish spermatozoa
}

\author{
USWATUN HASANAH ${ }^{1, \bullet}$, ABINAWANTO ${ }^{1, \bullet \bullet}$, A. ALIMUDDIN ${ }^{2}$, ARIEF BOEDIONO ${ }^{3}$, ENI KUSRINI ${ }^{4}$ \\ ${ }^{1}$ Department of Biology, Faculty of Mathematics and Natural Sciences, Universitas Indonesia. J1. Lingkar UI, Depok 16424, West Java, Indonesia. \\ Tel.: +62-21-7270163, Fax.: +62-21-78829010, `email: uzwah2603@gmail.com, ^^ abinawanto.ms@sci.ui.ac.id \\ ${ }^{2}$ Department of Aquaculture, Faculty of Fisheries and Marine Sciences, Institut Pertanian Bogor. Jl. Agatis, Kampus IPB Dramaga, Bogor 16680, West \\ Java, Indonesia \\ ${ }^{3}$ Department of Anatomy, Physiology, and Pharmacology, Faculty of Veterinary Medicine, Institut Pertanian Bogor. Jl. Agatis, Kampus IPB Dramaga, \\ Bogor 16680, West Java, Indonesia \\ ${ }^{4}$ Research Institute for Ornamental Fish Culture. Jl. Perikanan Raya, Pancoran Mas, Depok 16436, West Java, Indonesia
}

Manuscript received: 5 August 2020. Revision accepted: 8 September 2020.

\begin{abstract}
Hasanah U, Binawanto, Alimuddin A, Boediono A, Kursini E. 2020. Short Communication: Effect of cryopreservation on ultrastructure and mitochondrial function of albino Pangasius catfish spermatozoa. Biodiversitas 21: 4524-4528. Cryopreservation techniques have been carried out on many endangered species and animals with unique characteristics. Successful cryopreservation techniques vary between species depending on various factors. The study used cryopreserved spermatozoa of the albino Pangasius catfish as samples. The cryopreserved spermatozoa were analyzed by its ultrastructure, functional mitochondria, and viability. The cryopreservation was performed using a combination of $10 \%$ methanol, skim milk, and fish ringer extender. A deep freezer is used for cryopreservation at $-80{ }^{\circ} \mathrm{C}$ with a storage period of 14 days. Observations were made on fresh spermatozoa, post-equilibration spermatozoa, and frozen-thaw spermatozoa. This study found there were differences in ultrastructure and morphology in the three treatments. Fresh spermatozoa and post-equilibration spermatozoa appeared intact membrane, mitochondrial, and flagellar structures. In contrast, in frozen-thaw spermatozoa, there was damage to the cell membrane. The study showed different percentages of yields on functional mitochondria of fresh spermatozoa $(98 \pm 2 \%)$, spermatozoa post-equilibration $(57 \pm 7 \%)$, frozen-thaw spermatozoa (42 \pm $3.21 \%)$. Cell viability showed that there were differences in viability of fresh spermatozoa and frozen-thaw ( $\mathrm{p}<0.05)$, the results of fresh spermatozoa $(92 \pm 0.57 \%)$ spermatozoa post-equilibration $(80 \pm 3.51 \%)$, frozen-thaw spermatozoa $(61 \pm 2.30 \%)$. The study concluded that the spermatozoa cryopreservation affects the ultrastructure, mitochondrial function, and viability in albino Pangasius catfish spermatozoa.
\end{abstract}

Keywords: Albino Pangasius catfish, cryopreservation, mitochondrial function, spermatozoa, ultrastructure

\section{INTRODUCTION}

Sperm cryopreservation is a standard method for longterm germplasm storage, particularly in species of commercial interest, endangered species, and species with unusual genotypes (Carton-Garcia et al. 2013). Cryopreservation of spermatozoa functions as a genetic bank which can ensure genetic diversity and reproductive success (Viveiros et al. 2011). Spermatozoa are gamete cells made up of the head, mid-piece, and flagellum or tail compartments (Guo et al. 2016). The study of sperm structure and morphology provides information to optimize artificial reproduction (Islam and Akhter 2011). Knowledge of the sperm structure is also needed to develop sperm cryopreservation techniques and assess the potential for cell damage from contaminant exposure (Madhavi et al. 2015).

Morphology of the spermatozoa is a fertility-related parameter (Iswadi and Ann 2016). The structural integrity of the plasma membrane and the functional mitochondria of cells play an important role in fertilization ( $\mathrm{He}$ and Woods 2004). The mid-piece of the spermatozoa contains mitochondria associated with energy production, adenosine triphosphate (ATP) for spermatozoa motility (Guo et al. 2016). Recent sperm physiology studies have focused on mitochondria as the cell energy centers. Mitochondria are easily damaged organelles during cryopreservation and are responsible for most of the decrease in motility and fertility during the freezing and thawing processes. Differences in species indicate differences in energy requirements and optimal mitochondrial conditions. The cryopreservation processes cause damage to the plasma membrane and the mitochondrial of cells (Kopeika et al. 2005). Therefore, proper sperm handling techniques and storage media are needed to prevent sperm damage during the process of cryopreservation (Moraes and Meyers 2018).

The spermatozoa produced in many fish species have progressive motility with a short duration of 30 seconds to several minutes (Perchec 1995). For the success of cryopreservation, the use of cryopreservation protocols that can protect mitochondrial function and maintain the availability of ATP in fish spermatozoa is crucial. Methods able to investigate cellular damage such as transmission electron microscopy (TEM) can provide subcellular 
ultrastructural information to explain morphological changes. In the attempt to assess the plasma membrane integrity and mitochondrial function of the fish spermatozoa, fluorescence staining may be used (He and Woods 2004). Fluorescent staining such as rhodamine 123 (R 123) can measure mitochondrial function on fresh and cryopreserved spermatozoa (De Baulny et al. 1997). The Mitochondria of the dead sperm cells will fail to maintain green fluorescence after staining using rhodamine 123 (Evenson et al. 1982)

Ultrastructure analysis, mitochondrial function, and viability of spermatozoa in albino Pangasius catfish were carried out after cryopreservation. Albino Pangasius catfish is a valuable species of freshwater, known as an ornamental fish, and is a group of catfish with gene deviations. Gene deviations in albino Pangasius catfish cause fish to be easily stressed compared to other catfish species.

\section{MATERIALS AND METHODS}

\section{Spermatozoa collection}

The study was carried out during the season of reproduction (September-December 2019). Sperm was obtained from 6 males of albino Pangasius catfish. The fish collected were intramuscularly injected with a single dose of $0.5 \mathrm{~mL} / \mathrm{kg}$ body weight using the GnRH analog. After 10-12 hours of injection, the spermatozoa were stripped from the male by applying gentle pressure to the abdomen toward the urogenital orifice. The collected sperm were stored in a centrifuge tube $(15 \mathrm{~mL})$ at $4-5^{\circ} \mathrm{C}$ for further processing and analysis. This study was approved by ethical committee at Universitas Indonesia, Depok, Indonesia with permission number KET-294/UN2.F1/ETIK/PPM.00.02/2019.

\section{Spermatozoa cryopreservation}

$50 \mu \mathrm{L}$ of cement was diluted using an extender $(350 \mu \mathrm{L}$ of diluent solution (ringer), $50 \mu \mathrm{L}$ of skim milk, and $50 \mu \mathrm{L}$ of methanol 10\%) with a ratio of 1: 9 . Sperm in the extender was equilibrated at $4-5{ }^{\circ} \mathrm{C}$ for 10 minutes. The freezing process was carried out in a deep freezer with a temperature of $-80{ }^{\circ} \mathrm{C}$ for 14 days. The thawing process is carried out at a temperature of $40{ }^{\circ} \mathrm{C}$ for $1-2$ minutes until it melts (by immersing the cryotube into a water bath) (Horvath et al. 2003).

\section{Spermatozoa ultrastructure}

The samples were fixed in $0.1 \mathrm{M}$ cacodylate buffer containing glutaraldehyde of $2.5 \%$ and then centrifuged $3000 \mathrm{rpm}$ for 3 minutes. Afterward, samples were rinsed for 15 minutes with a $0.1 \mathrm{M}$ cacodylate buffer. Then, the sample was centrifuged for 3 minutes at $3000 \mathrm{rpm}$. Pellets were added with $2 \%$ osmium tetraoxide $+2.5 \% \mathrm{~K}_{3} \mathrm{fe}(\mathrm{CN})_{6}$ for 1 hour at $4{ }^{\circ} \mathrm{C}$. The samples were dehydrated using an ascending series of ethanol (50\% - 100\%). The sample was infiltrated with propylene oxide for 15 minutes at room temperature. The sample was embedded in epoxide resin. Then, ultra-thin sections of 50-70 nm thickness were made using a diamond knife. The section was placed on copper grids, stained with uranyl acetate and lead citrate, and screened under TEM (JEOL 1010) (Madhavi et al. 2015).

\section{Functional mitochondria}

A total of $10 \mu \mathrm{L}$ spermatozoa were incubated with 40 $\mu \mathrm{L}$ of rhodamine 123 (R 123 ) solutions $(13 \mu \mathrm{M})$ at $20^{\circ} \mathrm{C}$ for 10 minutes. Observation using a fluorescence microscope (Nikon Eclipse 80i) with excitation 465-495 $\mathrm{nm}$ (FITC channel). Sperm with positive rhodamine staining (green fluorescence) was considered to have functional mitochondria. In contrast, non-functional mitochondria were characterized by negative rhodamine staining (sperm without fluorescence) (He and Woods 2004; Bautista et al. 2018). The proportion of sperm that emits green fluorescence compared with total sperm (green or no fluorescence) determined the rate of mitochondrial function.

\section{Cell viability}

A total of $10 \mu \mathrm{L}$ of spermatozoa was dripped on the slide and mixed with $10 \mu \mathrm{L}$ of $0.5 \%$ eosin-Y solution, then covered with a cover glass. Observations were made with a bright field microscope. Spermatozoa with functional membrane integrity (viable) will not stain with eosin Y. In contrast, spermatozoa with damage to membrane integrity (non-viable) will appear red because they can be colored. Spermatozoa were observed as many as 100 cells with three repetitions of treatment.

\section{Statistical analysis}

Statistical analysis was performed using SPSS software version 23.0. The results were expressed as the percentage (mean \pm standard deviation), and were analyzed using a one-way ANOVA test with significance $\mathrm{P}<0.05$.

\section{RESULTS AND DISCUSSION}

\section{Spermatozoa ultrastructure}

Spermatozoa ultrastructure was observed in all 3 sample treatments (fresh, post-equilibration, and frozenthaw). Albino Pangasius catfish spermatozoa morphology is divided into three parts: the head, mid-piece, and single flagellum, are presented in Figure 1. Fish spermatozoa are widely divergent in form and structure, and sperm heads vary in diameters, and chromosomes in the nucleus undergo condensation and occupy most of the head. The mid-piece part consists of mitochondria. Mitochondria are found in the posterior region of the nucleus, which produces energy for the flagella movement.

Spermatozoa flagella is long and cylindrical. The flagellum is surrounded by a cell membrane that is projected to form two side fins, which are located on both sides of the flagellum and are not the same size. The axoneme structure is constructed from nine peripheral doublet microtubules and two central microtubules. The configuration pattern consists of ' $9+2$ structure with the central microtubules connected to the central pair bridge. Nine doublet microtubules are connected by an internal doublet link and surrounded by a plasma membrane. 


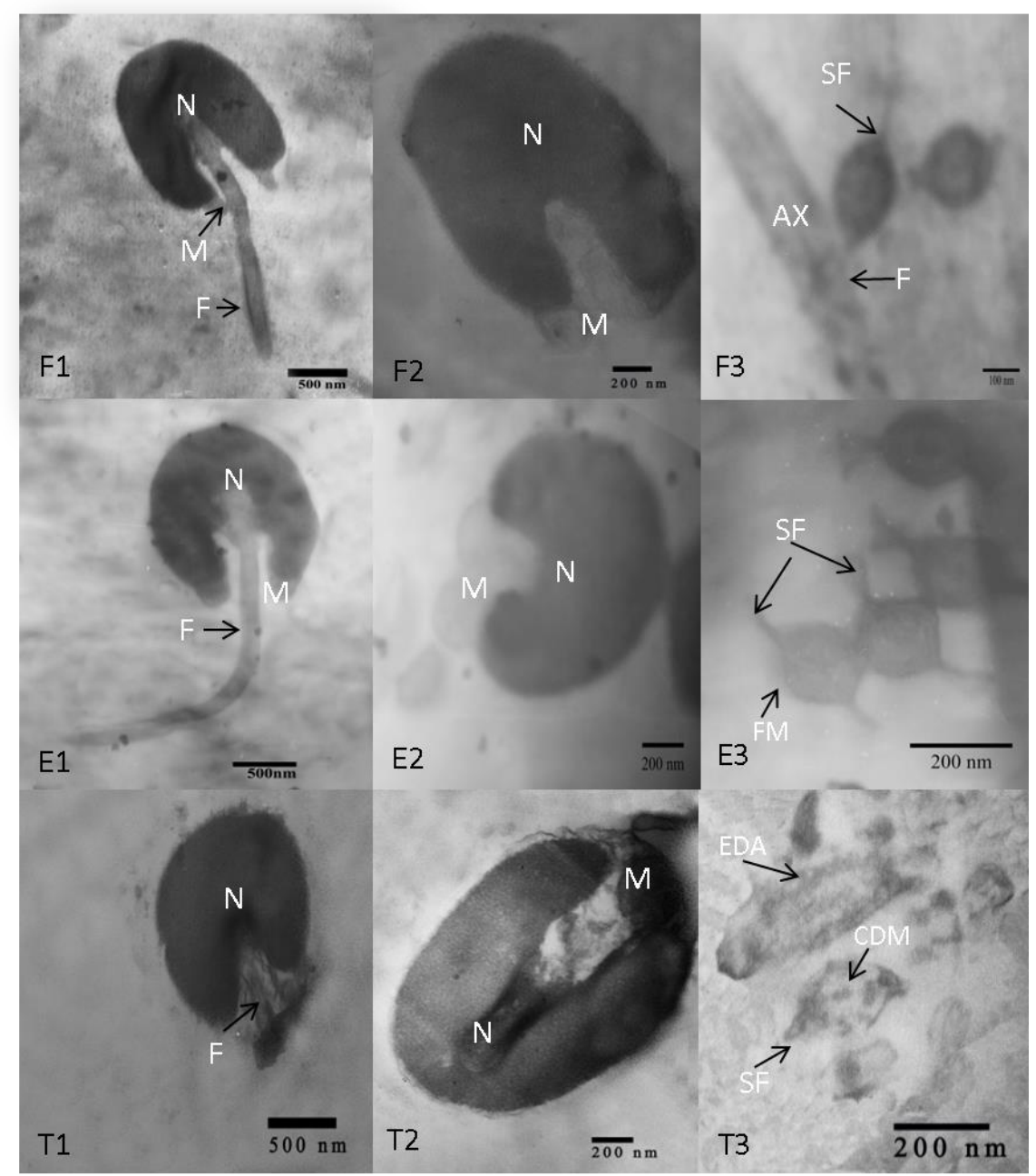

Figure 1. Ultrastructure of spermatozoa albino Pangasius catfish, with 3 treatments of fresh sperm (F1, F2, F3), Post-equilibration sperm (E1, E2, E3), frozen-thaw sperm (T1, T2, T3) with cell composition consisting of (N, nucleus; F, flagella; M, mitochondria; A, axoneme; SF, side fin; EDA, external dynein arms; CDM, central doublets of microtubules)

The effect of cryopreservation on the sperm ultrastructure, in fresh spermatozoa, is seen in the cell membrane, mitochondria, and flagellum are still intact. Post-equilibration spermatozoa appear to have extended sperm head width compared to fresh spermatozoa, but the structure of the sperm is still intact. While frozen-thaw sperm appear on the sperm head cell membrane damage occurs, mitochondria are damaged until the flagellum is cut off, are presented in Figure 1.

\section{Mitochondrial function}

The excellent function of mitochondria spermatozoa is a factor in the success of fertilization in species. The percentage of mitochondrial function in the treatment of fresh spermatozoa, spermatozoa post-equilibration, and frozen-thaw spermatozoa are $98 \pm 2 \%, 57 \pm 7 \%$, and $42 \pm 3.21 \%$ respectively, are presented in Figure 2 .

Sperm with positive rhodamine staining (green fluorescence) have functional mitochondria. In comparison, non-functional mitochondria are characterized by negative rhodamine staining (sperm without fluorescence). In fresh spermatozoa, it appears that almost all cells emit green during observation are presented in Figure 3.

\section{Spermatozoa viability}

The percentage of fresh spermatozoa that have viability or intact plasma membranes is $92 \pm 0.57 \%$. After 10 minutes of equilibration, there is a decrease to $80 \pm 3.51 \%$, and frozen-thaw to $61 \pm 2.30 \%$, which are presented in Figure 4. 


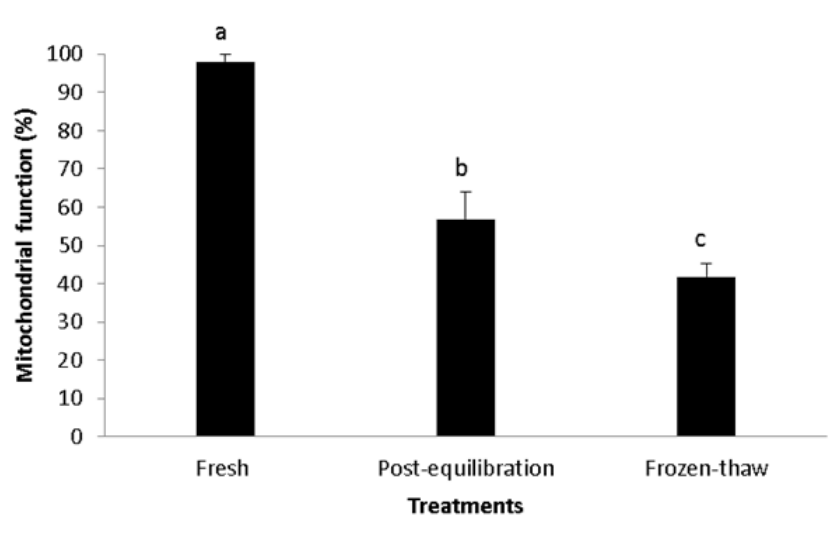

Figure 2. The function of mitochondria spermatozoa post cryopreservation of albino Pangasius catfish. The results were expressed as the percentage (mean \pm standard deviation) of spermatozoa cells. Bars with a different letter represent significant differences among treatments $(\mathrm{P}<0.05)$

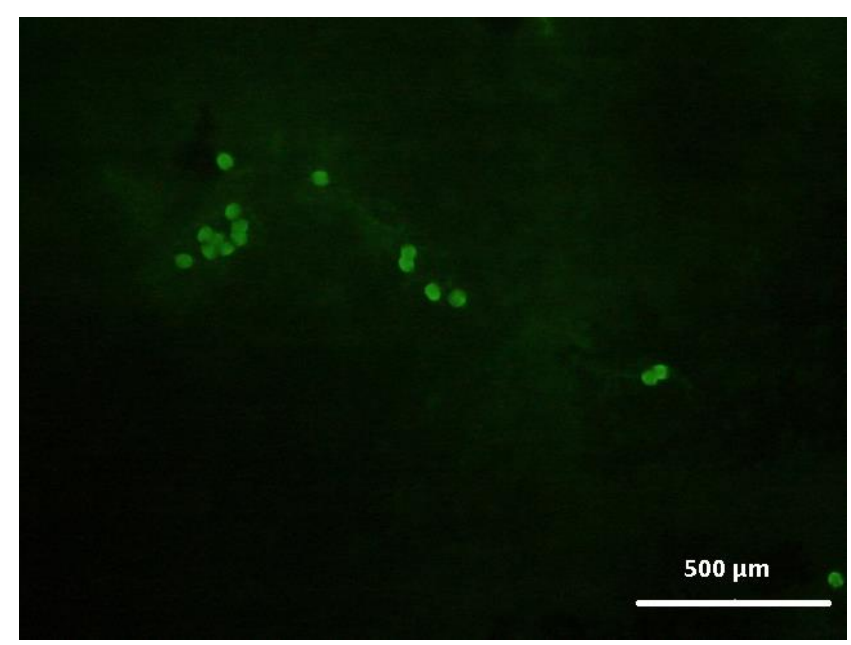

Figure 3. Overview of the function of mitochondrial spermatozoa in albino Pangasius catfish. Observations using a fluorescence microscope (Nikon Eclipse 80i) magnification of $100 \times 10$

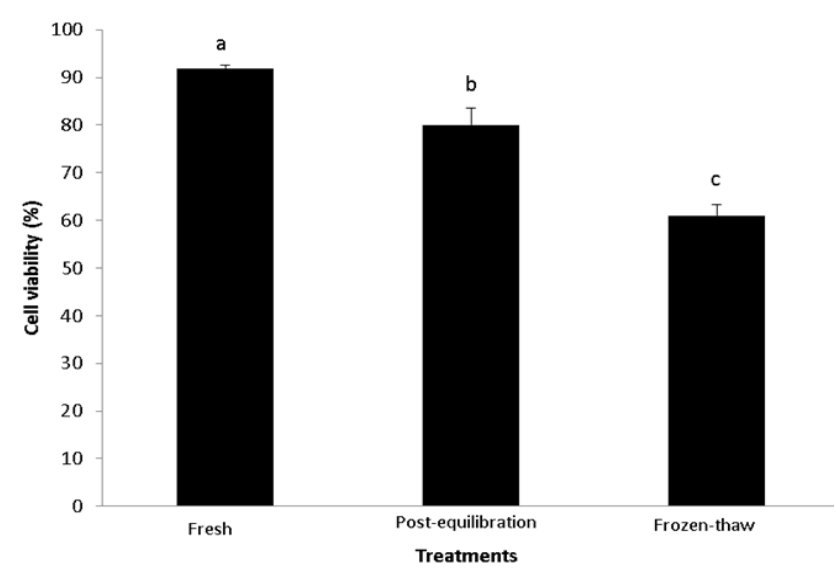

Figure 4. Viability of spermatozoa after cryopreservation of albino Pangasius catfish. The results were expressed as the percentage (mean \pm standard deviation) of spermatozoa cells. Bars with a different letter represent significant differences among treatments $(\mathrm{P}<0.05)$

\section{Discussions}

In this study, methanol was used as cryoprotectants. We found no significant damage to the plasma membranes, and the mitochondrial function of sperm was observed after cells were exposed to methanol concentrations $10 \%$, at 4 $5^{\circ} \mathrm{C}$ for $10 \mathrm{~min}$ in the equilibration process. The methanol enters the cell replacing the liquid that comes out to protect cells during the freezing process. A similar result was observed in common carp sperm prior to freezing with methanol as a cryoprotectant. Methanol is found nontoxic when used as a cryoprotectant and has been found superior to DMSO or glycerol in a number of cell types. Methanol has been successfully used for the cryopreservation of other fish such as the zebrafish (Danio rerio) (Harvey et al. 1982), catfishes (Tiersch et al. 1994), and salmonids (Lahnsteiner et al. 1997).

The study showed in fresh spermatozoa seen in the cell membrane, mitochondria, and flagellum are still intact. This phenomenon shows that the cell membrane and mitochondria are still in good condition to produce energy, and the flagellum, which consists of the axoneme structure is still in good shape for cell movement. Post-equilibration spermatozoa appear to have extended sperm head width compared to fresh spermatozoa. The cell membranes, mitochondria, and flagellates are still intact the same as in fresh spermatozoa. In the post-equilibration spermatozoa, the side fins were found on the flagellum when observing cross-sectional pieces. Although the function of the side fins is still unknown, it is suspected that the presence of side fins can accelerate the progression of the flagellum and also increase friction with the surrounding media, which results in an increased probability of successful fertilization. The presence of side fins is also found in some fish families, such as in Sparidae (Maricchiolo et al. 2004).

While frozen-thaw sperm appear on the sperm head cell membrane damage occurs, mitochondria are damaged until the flagellum is cut off. A cross-sectional and longitudinal observations of the flagellum also clearly visible damage to the axoneme flagellum. The thawing is a process in which methanol cryoprotectant comes out of the cell, and water enters back into the cell. Choosing the right temperature and melting time supports the success of the cryopreservation process. The temperature of $40{ }^{\circ} \mathrm{C}$ that is used is suspected not to be the optimal temperature of thawing, which is resulting in an imbalance condition, water too quickly enters the cell causing damage to the cell membrane, mitochondria, and flagellum. The other reason is that the spermatozoa membrane contains large amounts of monounsaturated, and polyunsaturated fatty acids are known to be susceptible to oxidative attack (Lahnsteiner et al. 2011).

The plasma membrane is the main structure of cells that are vulnerable to being affected during the cryopreservation process. Damage to the plasma membrane has been observed since sperm were exposed to cryoprotectants before the freezing process was seen from the sperm percentage with loss of viability and normal function of the plasma membrane during the freezing and thawing processes (He and Woods 2004). 
Fish spermatozoa generally have one to nine mitochondria that produce energy for sperm motility (Guo et al. 2016). Fish spermatozoa with external fertilization contain fewer mitochondria, no more than five mitochondria with a slightly elongated and not too large mid-piece (Lahnsteiner 2003). Mitochondria are one of the most easily damaged organelles during cryopreservation responsible for the loss of motility and fertility after freezing and thawing. Decreased mitochondrial function, sperm viability, and damage to membrane integrity can be caused by the freeze-thawing process during cryopreservation. The mitochondrion is damaged, which leads to a drop in the ATP content of the cells. Low ATP levels may then cause malfunction of ionic pumps and a destabilization of the plasma membrane (De Baulny et al. 1997).

In this study, we use fluorescent staining rhodamine 123 to measure mitochondrial function on fresh, post equilibration, and frozen-thaw spermatozoa. Rhodamine dyes were accumulated and maintained intensively in cells with good functional mitochondria. Mitochondria from dead cells failed to maintain rhodamin 123 after washing (Graham et al. 1990). In fish, it is imperative to maintain mitochondrial activity, because high motility usually only lasts for 30 seconds to several minutes.

During the freezing and thawing process, oxidative stress conditions can occur, namely an imbalance between the reactive production of oxygen species (ROS) and the ability of cells to repair the damage produced. Research on spermatozoa of Sparus aurata showed that after the cryopreservation of spermatozoa, the process of freezing and thawing produces ROS. The ROS being produced during cryopreservation can cause changes in chromatin levels, nitrogen base modification, strand damage, and DNA fragmentation (Carton-Garcia et al. 2013). Species differences indicate differences in energy requirements and the optimal conditions of the mitochondria. Mitochondrial energy requirements and optimal sperm conditions are varied between species, so it is crucial to optimize cryopreservation techniques and sperm handling (Moraes and Meyers 2018). The appropriateness of the media used for sperm processing and storage is also needed to provide an appropriate energy substrate to prolong the age of the sperm and prevent decreased sperm damage after cryopreservation.

After cryopreservation, changes in ultrastructure and mitochondrial function of albino Pangasius catfish spermatozoa cells were observed. In the future, research is expected to investigate the effect of cryopreservation on DNA integrity and genes related to cellular metabolism. In addition, the cryoprotectant composition also needs to be optimized to minimize cell damage.

\section{ACKNOWLEDGEMENTS}

The first author thanks the Indonesia Endowment Fund for Education (LPDP) for providing the research project fund.

\section{REFERENCES}

Bautista FEA., Junior ASV, Corcini CD, Acosta IB, Caldas SS, Primel, Zanette EGJ. 2018. The herbicide atrazine affects sperm quality and the expression of antioxidant and spermatogenesis genes in zebrafish testes. Toxicol Pharmacol 206: 17-22.

Carton-Garcia F, Riesco MF, Cabrita E, Herráez MP, Robles V. 2013. Quantification of lesions in nuclear and mitochondrial genes of Sparus aurata cryopreserved sperm. Aquac 402: 106-112.

De Baulny BO, Le Vern Y, Kerboeuf D, Maisse G. 1997. Flow cytometric evaluation of mitochondrial activity and membrane integrity in fresh and cryopreserved rainbow trout (Oncorhynchus mykiss) spermatozoa. Cryobiology 34 (2): 141-149.

Evenson DP, Darzynkiewicz Z, Melamed MR. 1982. Simultaneous measurement by flow cytometry of sperm cell viability and mitochondrial membrane potential related to cell motility. J Histochem Cytochem 30 (3): 279-280.

Graham JK, Kunze E, Hammerstedt RH. 1990. Analysis of sperm cell viability, acrosomal integrity, and mitochondrial function using flow cytometry. Biol Reprod 43 (1): 55-64.

Guo W, Shao J, Li P, Wu J, Wei Q. 2016. Morphology and ultrastructure of Brachymystax lenox tsinlingensis spermatozoa by scanning and transmission electron microscopy. Tissue Cell 48 (4): 321-327.

Harvey B, Kelley RN, Ashwood-Smith MJ. 1982. Cryopreservation of zebra fish spermatozoa using methanol. Can J Zool 60 (8): 18671870 .

He S, Woods C. 2004. Effects of dimethyl sulfoxide and glycine on cryopreservation induced damage of plasma membranes and mitochondria to striped bass (Morone saxatilis) sperm. Cryobiology 48 (3): 254-262.

Horvath Á, Miskolczi E, Urbányi B. 2003. Cryopreservation of common carp sperm. Aquat Living Res 16 (5): 457-460.

Iswadi MI, Ann ZF. 2016. Morphometry of head spermatozoa of sexually matured Malayan Gaur Bulls (Bos gaurus hubbacki). J Trop Agric Food Sci 44 (2): 315-324.

Islam MS, Akhter T. 2011. Tale of fish sperm and factors affecting sperm motility: a review. Adv Life Sci 1 (1): 11-19.

Kopeika J, Zhang T, Rawson DM, Elgar G. 2005. Effect of cryopreservation on mitochondrial DNA of zebrafish (Danio rerio) blastomere cells. Mutat Res/Fundam Mol Mech Mutagen 570 (1): 4961.

Lahnsteiner F, Weismann T, Patzner RA. 1997. Methanol as cryoprotectant and the suitability of $1.2 \mathrm{~mL}$ and $5 \mathrm{~mL}$ straws for cryopreservation of semen from salmonid fishes. Aquac Res 28 (6): 471-479.

Lahnsteiner F. 2003. The spermatozoa and eggs of the cardinal fish. J Fish Biol 62 (1): 115-128.

Lahnsteiner F, Mansour N, Kunz FA. 2011. The effect of antioxidants on the quality of cryopreserved semen in two salmonid fish, the brook trout (Salvelinus fontinalis) and the rainbow trout (Oncorhynchus mykiss). Theriogenology 76 (5): 882-890.

Madhavi M, Kailasam M, Mohanlal DL. 2015. Ultrastructure of sperm of the Spotted scat (Scatophagus argus, Linnaeus, 1766) observed by scanning and transmission electron microscopy. Anim Reprod Sci 153: 69-75.

Maricchiolo G, Genovese L, Laurà R, Micale V, Muglia U. 2004. Fine structure of spermatozoa in the common pandora (Pagellus erythrinus Linnaeus, 1758) (Perciformes, Sparidae). Histol Histopathol 19 (4): 1237-1240.

Moraes CR, Meyers S. 2018. The sperm mitochondrion: Organelle of many functions. Anim Reprod Sci 194: 71-80.

Perchec G, Jeulin C, Cosson J, Andre F, Billard R. 1995. Relationship between sperm ATP content and motility of carp spermatozoa. J Cell Sci 108 (2): 747-753.

Tiersch TR, Goudie CA, Carmichael GJ. 1994. Cryopreservation of channel catfish sperm: storage in cryoprotectants, fertilization trials, and growth of channel catfish produced with cryopreserved sperm. Trans Am Fish Soc 123 (4): 580-586.

Viveiros AT, Amaral TB, Orfao LH, Isau ZA., Caneppele D, Leal MC. 2011. Sperm cryopreservation of tiete tetra Brycon insignis (Characiformes): effects of cryoprotectants, extenders, thawing temperatures, and activating agents on motility features. Aquac Res 42 (6): 858-865. 